\title{
Suppressive effect of bacoside A on hypertrophic scar formation by downregulation of TGF- $\beta 1$
}

\author{
Zimiao Chen ${ }^{1}$, Lina Lü ${ }^{2 *}$ \\ ${ }^{1}$ Department of Burn Surgery, Yuncheng Central Hospital, Yuncheng, ${ }^{2}$ Institute of Hematological Diseases, The Third Hospital \\ of Yuncheng, Shanxi 044000, China
}

*For correspondence: Email: LAngelukit@yahoo.com; Tel: 0086-1860359024

Sent for review: 12 January 2018

Revised accepted: 25 August 2018

\begin{abstract}
Purpose: To determine the anti-scarring property of bacoside $A(B A)$ in a rabbit model of post-burns hypertrophic scar (HS).

Methods: A total of 16 healthy male rabbits were divided into four groups (4 rabbits/group). The rabbits were subjected to full-thickness burn wound by placing a 10 -mm brass rod at $90^{\circ} \mathrm{C}$ on their ears for 20 $s$, and were untreated (HS group). The remaining rabbits also underwent HS process but were topically treated daily with $0.2,0.4$ or $0.6 \% \mathrm{BA}$ gel (HS + 0.2, 0.4 , and $0.6 \% \mathrm{BA}$ groups) from day 8 to day 34 .

Results: The mean values of collagen (types I \& III), hydroxyproline (precursor of collagen) and hexosamine, as well as scar index significantly $(p<0.001)$ decreased after 28 days of topical treatment with BA. Moreover, BA application resulted in improved histological changes with proper arrangement of collagen fibers. Significant $(p<0.001)$ upregulation or downregulation of transforming growth factor beta-1 (TGF- $\beta 1$ ) and matrix metalloproteinase-1 (MMP-1) were observed in the BA-treated rabbits.

Conclusion: Treatment with $B A$ significantly lowers the scarring area of burn wounds by downregulation of TGF- $\beta 1$. Thus, BA can potentially be developed into a drug for managing injury scars.
\end{abstract}

Keywords: Hypertrophic scar, Bacoside A, Scar elevation index, Transforming growth factor beta-1, Collagen

\begin{abstract}
This is an Open Access article that uses a funding model which does not charge readers or their institutions for access and distributed under the terms of the Creative Commons Attribution License (http://creativecommons.org/licenses/by/4.0) and the Budapest Open Access Initiative (http://www.budapestopenaccessinitiative.org/read), which permit unrestricted use, distribution, and reproduction in any medium, provided the original work is properly credited.

Tropical Journal of Pharmaceutical Research is indexed by Science Citation Index (SciSearch), Scopus, International Pharmaceutical Abstract, Chemical Abstracts, Embase, Index Copernicus, EBSCO, African Index Medicus, JournalSeek, Journal Citation Reports/Science Edition, Directory of Open Access Journals (DOAJ), African Journal Online, Bioline International, Open-J-Gate and Pharmacy Abstracts
\end{abstract}

\section{INTRODUCTION}

Hypertrophic scar (HS) reflects the dysfunctional response from the skin during injury especially burns and surgery, which leads to excessive deposition of fibroblast and collagen and thick elevated scar/fibrosis [1]. Post-burn HS presents an emotional and physical burden on the patient owing to excessive pain, pruritus, discomfort, disability (joint contracture) and disfigurements [2]. Epidemiological studies have indicated that about $40-70 \%$ of thermal injury (burn wound) result in HS. Thus, there is need for its treatment as soon as possible [3]. To date, there are no effective treatment procedures or protocols for managing post-burn HS. However, a few treatment strategies (sub-optimal treatments) are employed efficiently to manage HS. These include silicone gel sheeting, massage therapy, laser surgery, and peptide therapy with natural products (combination therapy) [4]. 
The pathophysiology of HS is poorly understood. However, an ample amount of evidence implicate transforming growth factor beta-1 (TGF- $\beta 1$ ) and matrix metalloproteinase-1 (MMP-1) in HS formation because they are directly involved in collagen formation and deposition [5]. Therefore, any natural drug that can modulate these proteins may be beneficial for suppressing HS formation or for scar management. Bacoside $A$ $(B A)$ is a triterpenoid saponin isolated from Bacopa monniera L. (syn. Herpestis monniera). Several studies have reported that BA possesses various biological properties [6,7]. It exerts many pharmacological properties such as antiinflammatory, anti-stress, anti-oxidant, antimicrobial, neuroprotective, hepatoprotective and renoprotective effecs [8-10]. It co-exists with bacoside $B$ (BB). Being isomers, the two saponins differ only in their optical rotation (spatial configuration) [11].

Previously, Sharath et al [12] demonstrated that topical treatment with BA exhibited better wound healing property than standard dermal ointment (nitrofurazone). Moreover, saponins influence balance in the secretion of protease inhibitor in various models, and so might contribute to antiscarring property $[13,14]$. Therefore, the present animal study was designed to investigate the anti-scarring effect of BA in the rabbit ear scarring model by assessing various biochemical indices such epidermal thickness index (ETI) and scar elevation index (SEI), and collagen levels (Types I and III). In addition, glycosaminoglycans (hexosamine), protein levels of MMP-1 and TGF$\beta 1$ and histopathological alterations were studied.

\section{EXPERIMENTAL}

\section{Chemicals and BA gel preparation}

Lysis buffer, xylene, formaldehyde, toluene, hematoxylin and eosin ( $H$ \& E), and acetone were bought from Sigma-Aldrich (MO, USA). Other chemicals and reagents used in this study were of HPLC or analytical grade. The different concentrations of BA (for topical application) were prepared as reported by Sharath et al [12]. Different concentrations of BA gel $(0.2,0.4$ and $0.6 \% \mathrm{w} / \mathrm{w}$ gel) were prepared by adding 100 , 200 and $300 \mathrm{mg}$ of BA (each) to $50 \mathrm{~g}$ of sodium alginate.

\section{Experimental animals}

A total of sixteen male healthy adult New Zealand Albino rabbits weighing $2.4 \pm 0.4 \mathrm{~kg}$ were procured from the animal center at Shanxi University. The rabbits were housed in a polycarbonate cage, and were maintained under standard laboratory conditions (22 - $25{ }^{\circ} \mathrm{C}$; $55 \%$ humidity) with 12-h light/dark cycle, and unlimited access to water and food. This study was approved by the ethical committee of The Third Hospital of Yuncheng (approval no. THY-150052). All the animal procedures/protocols were performed based on $\mathrm{NIH}$ guidelines.

\section{Procedure for HS production}

Thermal injury was used for inducing HS in line with the method of Friedrich and his colleagues [15], but with slight modifications. The rabbits were anesthetized with meloxicam $(0.2 \mathrm{mg} / \mathrm{kg})$ and xylazine $(5 \mathrm{mg} / \mathrm{kg})$ under sterile conditions. On the contralateral ear, four $10-\mathrm{mm}$ deep, fullthickness thermal wounds (burn wound) were made by placement of $10-\mathrm{mm}$ brass rod at $90 \stackrel{\circ}{\circ}$ for $20 \mathrm{~s}$ using Fisher dry bath incubator (Fisher Scientific, PA, USA). Each ear received 4 burn wounds with full removal of epidermis, dermis and perichondrium. All the thermal wounds were covered with a sterile Tegaderm occlusive dressing for the first three days to prevent cartilage desiccation. After the HS procedure, the rabbits were returned to their respective cages (after recovery from anesthesia) and placed with an Elizabethan collar to avoid wound infection between rabbits. They were inspected daily for topical application and also to confirm any infection or any discomfort.

\section{Experimental design}

Sixteen rabbits were divided into four groups (4 in each group) with 32 scars in each group. Group I rabbits were inflicted $10-\mathrm{mm}$ deep fullthickness thermal wound as indicated above without any treatment, and they formed the HS group. Groups II, III and IV rabbits also underwent HS procedure but were topically treated daily with 0.2 or 0.4 or $0.6 \%$ BA gel from the $8^{\text {th }}$ day to the $34^{\text {th }}$ day.

\section{Sample preparation}

On the $35^{\text {th }}$ day, overnight fasted rabbits were sacrificed by cervical decapitation. The scar samples were harvested immediately from each rabbit (8 scars in each rabbit) and stored at -80 ${ }^{\circ} \mathrm{C}$ until use. For histological analysis, a small portion of scar tissue was fixed in $10 \%$ formaldehyde. The remaining scar tissues were homogenized with Tris-phosphate buffer (lytic buffer) and centrifuged at $3500 \mathrm{rpm}$ for $15 \mathrm{~min}$ at $4 \stackrel{\circ}{ } \mathrm{C}$, and the resultant supernatant was used for biochemical and molecular assays. Protein levels in the scar tissue homogenate were determined 
using a protein quantification kit (Bradford Assay) purchased from Abcam (Cambridge, UK).

\section{Determination of collagens and glycosamino- glycans}

Collagen types I and III contents in the scar tissues were determined using commercial ELISA kit purchased from R \& D Systems (MN, USA) based on the supplier's protocol, and expressed as $\mathrm{mg} / \mathrm{g}$ scar tissue. Hexosamine and hydroxyproline levels in the scar tissues (homogenate) were estimated by the methods of Wagner [16] and Woessner [17], respectively. Both hexosamine and hydroxyproline were expressed as $\mathrm{mg}$ per $100 \mathrm{mg}$ scar tissue.

\section{Histological evaluation}

The formaldehyde-fixed scar tissues were dehydrated and processed with xylene and acetone, followed by embedding in paraffin wax. They were then sectioned into $4-\mu \mathrm{m}$ diameter slices using a microtome, fixed in microscope slides and stained with $\mathrm{H}$ \& $\mathrm{E}$ stain for $8 \mathrm{~h}$ at $37^{\circ} \mathrm{C}$. Finally, the scar tissue slides were viewed using light microscopy by a professional pathologist to assess any histological changes. Pictures of salient features were captured by the pathologist.

\section{Assessment of scar index}

Scar elevation index (SEI) and epidermal thickness index (ETI) were determined based on hematoxylin and eosin (H \& E) staining images captured by light microscope (Olympus Co., Tokyo, Japan) and analyzed with ImageJ software (ver 5.1; NIH, MD, USA). The images were graded by the method of Zhao et al [26]. Here, SEI corresponded to the ratio of total scar area (wound area) to the area of underlying dermis formed (normal tissue). An index $>1$ indicated HS formation, but an idex of 1 meant no newly formed HS. On the other hand, ETI, represented by the degree of hypertrophy, was calculated as the ratio of mean epidermal height (cm) of scar tissue to mean epidermal height (cm) of normal tissue. An ETI > 1 indicated hypertrophic epidermal formation.

\section{Quantification of MMP-1 and TGF- $\beta 1$ by western blot}

An equal quantity $(40 \mu \mathrm{g})$ of protein extract of scar tissue homogenate was transferred onto polyacrylamide gel (10\%) and separated by SDS-PAGE technique. Then the gel was electrotransferred onto polyvinylidene difluoride (PVDF) membrane. The membrane was blocked using Tris-phosphate buffer solution (TPBS) with tween 20 and $5 \%$ skimmed milk. It was then probed for $10 \mathrm{~h}$ at $37^{\circ} \mathrm{C}$ with primary antibodies: rabbit monoclonal anti-matrix metalloproteinase1 (MMP-1) and anti-transforming growth factor beta-1 (TGF- $\beta 1$ ) at dilutions of 1:1000 and 1:800, respectively (Zhongshan Biotechnology, Beijing, China) and housekeeping gene $\beta$-actin (1:800; Zhongshan Biotechnology, Beijing, China). This was followed by incubation with secondary antibody conjugated with polyclonal anti-rabbit horseradish peroxidase (HRP) antibody (1:10,000; Abcam, Cambridge, UK) for $1 \mathrm{~h}$ at 37 ${ }^{\circ} \mathrm{C}$. To remove unbound antibodies, the membrane was washed with TPBS solution. The protein bands were visualized with an enhanced ECL kit and photographed using chemiluminescent image analyzer (ChemiDoc; Bio-Rad Laboratories, Inc., Hercules, CA, USA). The specific proteins were quantified using ImageJ software (5.1 ver) from NIH (MD, USA).

\section{Statistical analysis}

Data are presented as mean \pm standard deviation $(S D, n=4)$ ). Significant differences between HS and BA treatment groups at different BA concentrations were determined using oneway ANOVA, and by Dunnett's multiple comparison test. All statistical analyses were done using Statistical Package for the Social Sciences (Ver 21, IBM, NY, USA). Values of $p<$ 0.05 were considered to indicate statistically significant difference.

\section{RESULTS}

\section{Collagens and glycosaminoglycans}

The effect of BA on collagen types I and III, and glycosaminoglycans in the experimental rabbits are shown in Figure $1 \mathrm{~A}$ and Figure 1B, respectively. The values of collagen (types I \& III), hydroxyproline (precursor of collagen) and hexosamine were significantly decreased $(p<$ $0.05)$ by topical application of BA in a concentration-dependent manner, when compared to HS group.

\section{Histopathological changes}

Figure 2 illustrates the effect of BA on scar tissue histo-morphology as revealed by $\mathrm{H}$ \& E staining. The scar tissue section of HS rabbits (positive control) revealed the presence of excessively scattered fibroblasts with an irregular arrangement of collagen fibers leading to thickened dermal layers (projection). However, in the $0.2 \%$ BA-treated rabbit scar tissue (Figure 2 $B)$, there were moderate amounts of fibroblasts 

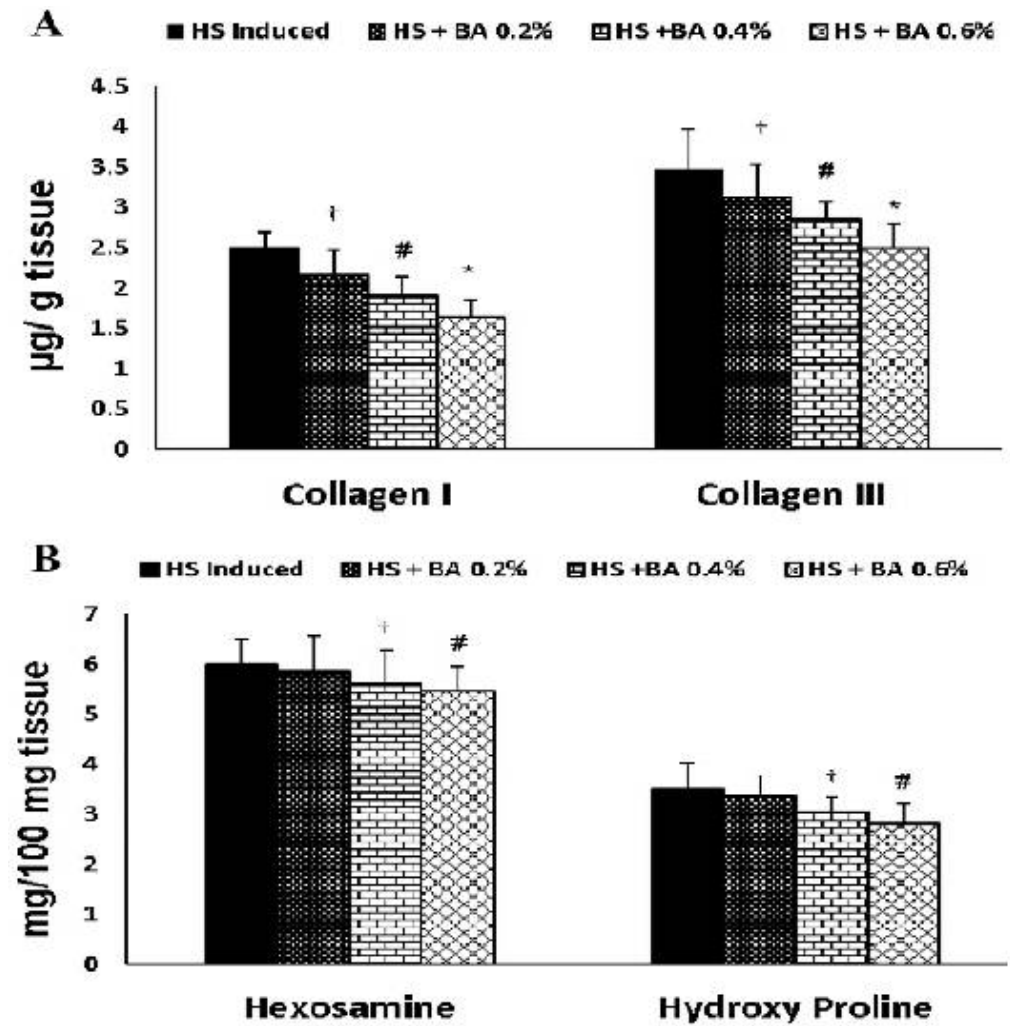

Figure 1: Effect of BA on collagen types (I and III; A) and glycosaminoglycans (B) in the experimental rabbits. The values are presented as mean \pm SD $(n=4) . \dagger p<0.05,{ }^{\#} p<0.01, p<0.001$, compared with BA treatment group (HS vs. 0.2 or 0.4 or $0.6 \%$ BA gel)

and slightly thicker dermal layers with few irregularly arranged collagen fibers. The scar tissue section of $0.4 \%$ BA-treated rabbits (Figure 2 C) showed lesser amounts of fibroblasts with better collagen fiber arrangements, and much thinner dermal layers. Topical treatment with 0.6 $\%$ BA gel for 28 days resulted in regularlyarranged collagen fibers with thinner dermal layers devoid of any projections (Figure $2 \mathrm{D}$ ).

\section{Scar index}

The effect of BA on the $\mathrm{SCl}$ and ETI in the experimental rabbits are shown in Figure $3 \mathrm{~A}$ and Figure 3B, respectively. As the concentration of $\mathrm{BA}$ increased $(0.2$ to $0.6 \%)$, the levels of SEI and ETI were significantly decreased, relative to the HS group $(0.2 \%, p<0.05 ; 0.4 \%, p<0.01$; $0.6 \%, p<0.001)$.

\section{Protein expression of MMP-1 and TGF- $\beta 1$}

Figure 4 shows the effect of $B A$ on the protein expressions of TGF- $\beta$ and MMP-1 in the scar tissue homogenate of the rabbits. The protein expressions of TGF- $\beta$ and MMP-1 were upregulated or downregulated in a dosedependent fashion on treatment with $\mathrm{BA}$, when compared with the HS group $(0.2 \%, p<0.05$;
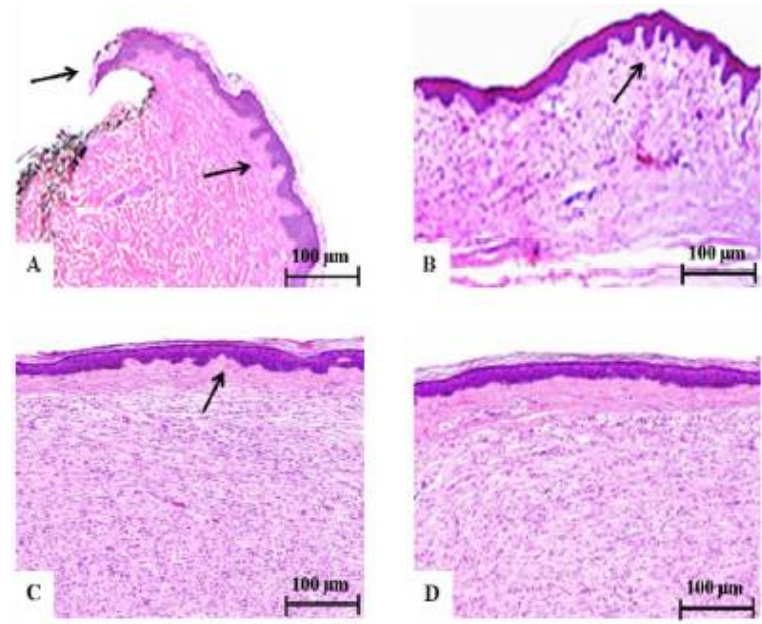

Figure 2: Effect BA on scar tissue histopathology $(\mathrm{H}$ \& E staining; $\times 40$ ); $2 A$ : HS rabbit (positive control; scar tissue section revealed an irregular arrangement of collagen fibers with thickened dermal layers (projections denoted by arrow); 2B: $0.2 \%$ BA-treated rabbit scar tissue showing lesser irregularly arranged collagen fibers with thicker dermal layers (arrowed); 2C: scar tissue section of $0.4 \%$ BA-treated rabbits showing better collagen fiber arrangements with thinner dermal layers (arrowed); 2D: scar tissue section treated with $0.6 \% \mathrm{BA}$ for 28 days showing arranged collagen fibers with thinner dermal layers without any projections (arrowed) $0.4 \%, p<0.01 ; 0.6 \%, p<0.001)$. 


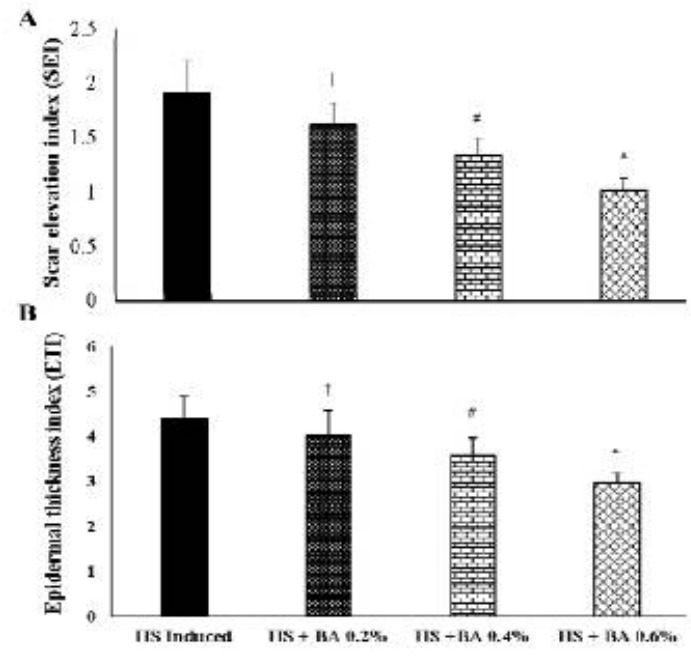

Figure 3: Effect of BA on scar elevation index (SEI) and epidermal thickness index (ETI) in experimental rabbits. The values are presented as mean \pm SD $(n=$ 4). ${ }^{\dagger} p<0.05,{ }^{\sharp} p<0.01,{ }^{\star} p<0.001$, compared with BA treatment group (HS vs. 0.2 or 0.4 or $0.6 \% \mathrm{BA}$ gel)

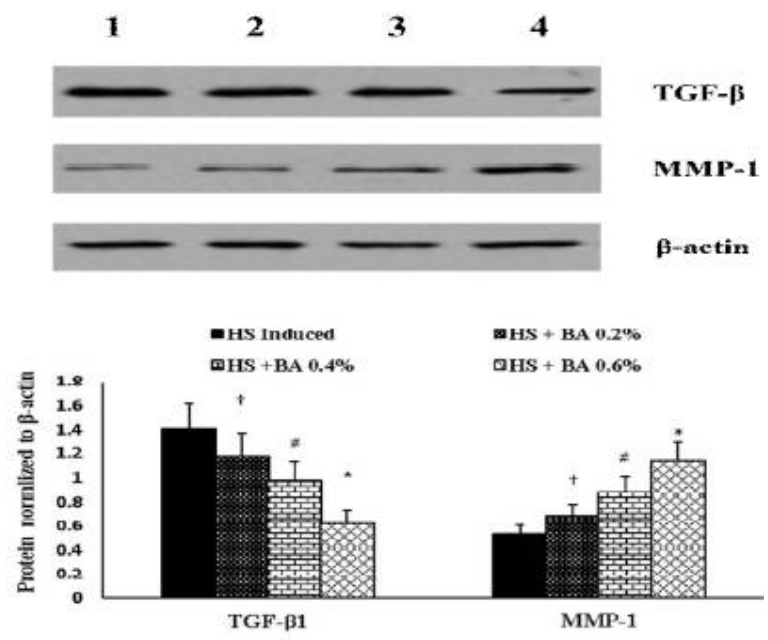

Figure 4: Effect of BA on the protein expressions of MMP-1 and TGF- $\beta 1$ in experimental rabbits. Lane 1 represents HS group; lanes 2 to 4 represent $\mathrm{HS}+0.2$ $\% \mathrm{BA}, \mathrm{HS}+0.4 \% \mathrm{BA}$ and $\mathrm{HS}+0.6 \%$ BA groups, respectively. The values are presented as mean \pm SD $(\mathrm{n}=4) .{ }^{\dagger} p<0.05,{ }^{\#} p<0.01, p<0.001$, compared with BA treatment groups (HS vs. $0.2,0.4$ and $0.6 \%$ BA gel) (TGF- $\beta 1$ : transforming growth factor beta-1; MMP1: matrix metalloproteinase-1)

\section{DISCUSSION}

The present study was designed to investigate the anti-scarring property of BA in post-burn, hyper scarring rabbit ear model. The results showed that all concentrations of BA used (0.2, 0.4 or $0.6 \%$ ) lowered scar formation. However, the best anti-scarring effect was produced with $0.6 \%$ BA. During wound healing process, the production/synthesis of collagen and GAGs act as a double-edged sword: they enhance the healing process, but excessive production or deposition may result in HS formation. Hence, the balance between degradation and synthesis of collagen plays a vital role in scarring process $[18,19]$. The contents of collagen (types I \& III), hydroxyproline and hexosamine (GAG) were considerably decreased on topical treatment with increasing doses of BA gel (0.2 to $0.6 \%$ ). These results are in agreement with that of Fang et al [20].

To further demonstrate the anti-scarring effect of $\mathrm{BA}$, histopathological changes in the scar tissues were evaluated. The positive control scar tissue (HS) showed increased presence of scattered fibroblasts with irregular arrangement of collagen fibers/bundles which resulted in thickened dermal layers. Likewise, Wei and his colleagues demonstrated that untreated scar tissue (HS model) showed thickened dermal layers with excessive disarrangement of collagen fibers [5]. Topical treatment with BA for 28 days reversed those abnormal histological changes, resulting in collagen fibers with thin dermal layers, with $0.6 \%$ BA showing the best histology which was similar to normal scar with regularly arranged collagen fibers or bundles. Similarly, it has been reported that treatment of burn scar with $0.5 \%$ of asiaticoside (saponin from Centella asiatica) resulted in collagen fiber arrangements similar to control scar tissue [21].

The scar index levels were substantially increased in HT rabbits, but on treatment with increasing concentrations of BA (0.2 to $0.6 \%)$, the levels of SEI and ETI were significantly reduced, possibly due to decreased collagen deposition. Studies have shown that treatment with Bacopa monniera remarkably lowered burn scar area [8]. Matrix metalloproteinases (MMPs) are collectively called as matrixins. They are calcium-dependent zinc containing proteinases which play crucial roles in extracellular matrix (ECM) protein degradation and are thus involved in wound healing and scar/keloid formation [22]. However, MMP-1 (collagenase) is of one the pivotal proteolytic enzymes that is involved directly in the degradation of collagen types I and III in scarring tissue, and so serves as a major marker of tissue remodeling such as wound healing and scar/keloid formation [5]. Therefore, to evaluate the role of MMP-1 in scar formation, the protein expression of MMP-1 was assayed using western blot technique. The MMP-1 protein expression was significantly upregulated after 28 days of treatment with BA in a dose-dependent fashion. This is in agreement with a report showing that treatment with opuntia (rich in saponins) for 54 days significantly increased the expression of MMP-1 in a hypertrophic scar rabbit model [20]. The results obtained in this 
study indicate that BA positively modulates MMP-1 protein expression and thereby reduces excessive collagen deposition in the wound/scar tissue.

Transforming growth factor- $\beta$ (TGF- $\beta$ ) exists in three isoforms (TGF- $\beta 1$ to 3 ). It plays a unique role in various pathological conditions especially wound healing and scarring [23]. Abundant evidence have demonstrated that hypertrophyderived fibroblasts of $\mathrm{HS}$ tissue are highly active (for a long time) and so they significantly upregulate the protein expression of TGF- $\beta 1$ more than the other isoforms [24]. The protein expression of TGF- $\beta 1$ was markedly downregulated by treatment with increasing concentrations of $\mathrm{BA}(0.2$ to $0.6 \%)$, relative to the HS group. Similarly, it has been reported that asiaticoside, a saponin isolated from Centella asiatica significantly downregulated the protein expression of TGF- $\beta 1$ by modulating TGF$\beta /$ Smad signaling pathway in hypertrophic scarring rabbit model [22].

\section{CONCLUSION}

Topical treatment with BA significantly lowers the scarring area and scarring thickness of rabbit ear in a dose-dependent fashion following a thermal wound, by reducing collagen (types I and III), GAG contents, and SEI and ETI levels. These changes are due to upregulation or downregulation of MMP-1 or TGF- $\beta 1$ proteins. Therefore, BA possesses a potential for use in the development of drugs for suppression of scar formation (HS).

\section{DECLARATIONS}

\section{Acknowledgement}

Authors like to thank The Third Hospital Of Yuncheng, Shanxi, China (Committee Members) for providing funds to conduct this study.

\section{Conflict of Interest}

No conflict of interest associated with this work.

\section{Contribution of Authors}

The authors declare that this work was done by the authors named in this article and all liabilities pertaining to claims relating to the content of this article will be borne by them.

\section{REFERENCES}

1. Kryger ZB, Sisco M, Roy NK, Lu L, Rosenberg D, Mustoe TA. Temporal expression of the transforming growth factor-Beta pathway in the rabbit ear model of wound healing and scarring. J Am Coll Surgeons 2007; 205(1): 78-88.

2. Chiang RS, Borovikova AA, King K, Banyard DA, Lalezari $S$, Toranto JD, Paydar KZ, Wirth GA, Evans GR, Widgerow $A D$. Current concepts related to hypertrophic scarring in burn injuries. Wound Repair Regen 2016; 24 : 466-477.

3. Lawrence JW, Mason ST, Schomer K, Klein MB. Epidemiology and impact of scarring after burn injury: a systematic review of the literature. $J$ Burn Care Res 2012; 33: 136-46.

4. Arno Al, Gauglitz GG, Barret JP, Jeschke MG. New molecular medicine-based scar management strategies. Burns 2014; 40(4): 539-551.

5. Wei YJ, Yan XQ, Ma L, Wu JG, Zhang $H$, Qin $L P$. Oleanolic acid inhibits hypertrophic scarring in the rabbit ear model. Clin Exp Dermatol 2011; 36(5): 528-533.

6. Kishore L, Kaur N, Singh R. Bacosine isolated from aerial parts of Bacopa monnieri improves the neuronal dysfunction in Streptozotocin-induced diabetic neuropathy. J Funct Foods 2017; 34: 237-247.

7. Deepak M, Amit A. The need for establishing identities of 'bacoside $A$ and $B$ ', the putative major bioactive saponins of Indian medicinal plant Bacopa monnieri. Phytomed 2004; 11(2-3): 264-268.

8. Murthy S, Gautam MK, Goel S, Purohit V, Sharma H, Goel RK. Evaluation of in vivo wound healing activity of Bacopa monniera on different wound model in rats. BioMed Res Int 2013; 2: 2013.

9. Anbarasi K, Vani G, Balakrishna K, Devi CS. Effect of bacoside $A$ on brain antioxidant status in cigarette smoke exposed rats. Life Sci 2006; 78: 1378-1384.

10. Kishore L, Kaur N, Singh R. Renoprotective effect of Bacopa monnieri via inhibition of advanced glycation end products and oxidative stress in STZ-nicotinamideinduced diabetic nephropathy. Renal Failure 2016; 38(9): 1528-1544.

11. Rastogi S, Pal R, Kulshreshtha DK. Bacoside A3 -a triterpenoid saponin from Bacopa monniera. Phytochem 1994; 36: 133-137.

12. Sharath $R$, Harish $B G$, Krishna V, Sathyanarayana $B N$, Swamy HM. Wound healing and protease inhibition activity of Bacoside-A, isolated from Bacopa monnieri wettest. Phytother Res 2010; 24(8): 1217-1222.

13. Wang HJ, Gao WC, Ma SL. Effect of Abnormal Savda Munziq on hypertrophic scar formation in a rabbit ear model. Chin J Integ Med 2015; 21(7): 537-541.

14. Azeez S, Amudhan S, Adiga S, Rao N, Udupa LA. Wound healing profile of Area Catechu extract on different wound models in wistar rats. Kuwait Med $J$ 2007; 39: 48-52

15. Friedrich EE, Niknam-Bienia S, Xie P, Jia SX, Hong SJ, Mustoe TA, Galiano RD. Thermal Injury Model in the Rabbit Ear with Quantifiable Burn Progression and 
Hypertrophic Scar. Wound Repair Regen 2017; 25(2): 327-337.

16. Wagner WD. A more sensitive assay discriminating galactosamine and glucosamine in mixtures. Anal Biochem 1979; 94(2): 394-396.

17. Woessner JF. The determination of hydroxyproline in tissue and protein samples containing small proportions of this imino acid. Arch Biochem Biophys 1961; 93: 440447.

18. Zhao Y, Li X, Xu X, He Z, Cui L, Lv X. Lumican alleviates hypertrophic scarring by suppressing integrin-FAK signaling. Biochem Biophys Res Commun 2016; 480(2): 153-159.

19. Mehta M, O Branford, $K$ Rolfe. The evidence for natural therapeutics as potential anti-scarring agents in burnrelated scarring. Burns Trauma 2016; 4(1): 15-19.

20. Fang $Q$, Ma SL, Dong XL. The effect of the extract of opuntia on the expression of type $I$ and III collagen and MMP-1 of hypertrophic scar in rabbits ears. $J$ Xinjiang Med Univ 2007; 6: 9-14.
21. Tang B, Zhu B, Liang $Y$, Bi L, Hu Z, Chen B, Zhang $K$, Zhu J. Asiaticoside suppresses collagen expression and TGF- $\beta /$ Smad signaling through inducing Smad7 and inhibiting TGF- $\beta R I$ and TGF- $\beta R / I$ in keloid fibroblasts. Arch Dermatol Res 2011; 303(8): 563-572.

22. Ulrich $D$, Ulrich $F$, Unglaub $F$, Piatkowski $A$, Pallua $N$. Matrix metalloproteinases and tissue inhibitors of metalloproteinases in patients with different types of scars and keloids. J Plast Reconstr Aesthet Surg 2010; 63(6): 1015-21.

23. $Y u$ H, Zitron S, Bayat A, Ferguson MW, Mrowietz U. Studies of transforming growth factors beta 1-3 and their receptors $i$ and ii in fibroblast of keloids and hypertrophic scars. Acta Dermato-venereologica 2005; 85(3): 216-220

24. Penn JW, Grobbelaar AO, Rolfe KJ. The role of the TGF$\beta$ family in wound healing, burns and scarring: a review. Int J Burns Trauma 2012; 2(1): 18-22. 